\title{
Efficiency YAG Laser PI (Peripheral Iridotomy) in Management of Glaucoma Patients in Bangladesh
}

Dr. Md. Kamrul Islam ${ }^{1 *}$, Dr. Md. Nasir Uddin², Dr. AKM Shamsuddin ${ }^{3}$

${ }^{1}$ Assistant Professor, (Eye), Patuakhali Medical College, Patualhali, Bangladesh

${ }^{2}$ Assistant Professor, (Eye), Sher e Bangla Medical College, Barishal, Bangladesh

${ }^{3}$ Assistant Professor, Paediatric Surgery, Sir Solimullah Medical College, Dhaka, Bangladesh

DOI: $10.36347 /$ sjams.2020.v08i06.033

| Received: 18.06.2020 | Accepted: 25.06.2020 | Published: 27.06.2020

*Corresponding author: Dr. Md. Kamrul Islam

Abstract

Original Research Article

Objective: In this study our main goal is to evaluate the efficiency of YAG laser PI (peripheral iridotomy) in management of glaucoma patients in Bangladesh. Method: This cross-sectional study was done in the in the National Institute of Ophthalmology \& Hospitalfrom March 2019 to March 2020.A total of 180 consecutive patients were included. On the basis of Academy of Ophthalmologyprimary Angle Closure glaucomapreferred practice pattern patients were sub divided into three group: primary angle closure suspect (PACS) (\#180 iridotrabecular contact [ITC], normal IOP and no optic nerve damage), $n=60$ : primary angle closure (PAC) $\left(\$ 180^{\circ}\right.$ ITC with peripheral anterior synechiae [PAS] or elevated IOP, but no optic neuropathy), $n=60$; and primary angle closure glaucoma (PACG) ( $\$ 180^{\circ}$ ITC with PAS, elevated IOP and optic neuropathy, $n=60$. Result: during the study, $42 \%$ percent of the patients had undergone bilateral LPI. $\%$ produced hyphema in $1^{\text {st }}$ year, followed by $1 \%$ produced hyphema in ${ }^{2 \text { nd }}$ year, no patients found in $3^{\text {rd }}$ year. mean power used in primary angle closure glaucoma was $132 \pm 127.8$. On the basis of Logmar chart, mean percentage of visual acuity where before treatment visual acuity of the primary angle closure suspect was $81 \%$, which was $3 \%$ increased after treatment, $84 \%$. Conclusion: From our study we can conclude that, laser iridotomy can be use as beneficial tool for the clinical treatment of early primary angle-closure glaucoma which can effectively reduce the intraocular pressure and improves the acuity level of patient. Early treatment by laser iridotomy may also reduce the risk rate to developprimary angle glaucoma.

Keyword: YAG laser PI (peripheral iridotomy), primary angle closure glaucoma, and primary angle closure.

Copyright @ 2020: This is an open-access article distributed under the terms of the Creative Commons Attribution license which permits unrestricted use, distribution, and reproduction in any medium for non-commercial use (NonCommercial, or CC-BY-NC) provided the original author and source are credited

\section{INTRODUCTION}

Glaucoma is a group of eye conditions that damage the optic nerve, the health of which is vital for good vision. This damage is often caused by an abnormally high pressure in eye. If the damage worsens, glaucoma can cause permanent vision loss or even total blindness within a few years [1].

Recent studies also have implicated low intracranial pressure (the pressure that surrounds the brain) as one of the risks for glaucoma [2-3].

YAG laser PI (peripheral iridotomy) has been widely used and accepted as a treatment for all forms of angle closure glaucoma in which there is a component of pupillary block and is used as a prophylactic treatment for angle closure suspects[1,2]. During ophthalmology residency training, the Accreditation Council for Graduate Medical Education (ACGME) currently recommends that all residents perform a minimum of 5 LPI procedures prior to graduation [3]. Although LPIs are generally considered safe, complications are known to occur. Complications include transient blurred vision, intraocular pressure (IOP) rise, dysphotopsia, hyphema, closure of the iridotomy and damage to other tissues $[1,2,4]$.

In this study our main goal is to evaluate the efficiency of YAG laser PI (peripheral iridotomy) in management of glaucoma patients in Bangladesh.

\section{OBJJECTIVE}

General objective

- To evaluatethe efficiency of YAG laser PI (peripheral iridotomy) in management of glaucoma patients in Bangladesh

\section{Specific objective}

- To detect clinical characteristics of patients.

- To identify complication rates by year of the patients. 


\section{Methodology}

\begin{tabular}{|l|l|}
\hline Type of study & Cross sectional study. \\
\hline Place of study & National Institute of Ophthalmology \& Hospital \\
\hline Study period & March 2019 to March 2020 \\
\hline Study population & $\begin{array}{l}180 \text { consecutive patients of primary angle closure, primary angle closure suspects and } \\
\text { glaucoma who presented to the glaucoma services. }\end{array}$ \\
\hline Sampling technique & Purposive \\
\hline
\end{tabular}

\section{METHOD}

- On the basis of Academy of Ophthalmology Primary Angle Closure Preferred Practice Pattern patients were sub divided into three group: primary angle closure suspect (PACS) $\left(\# 180^{\circ}\right.$ iridotrabecular contact [ITC], normal IOP and no optic nerve damage), $n=60$ : primary angle closure (PAC) $\quad\left(\$ 180^{\circ}\right.$ ITC with peripheral anterior synechiae [PAS] or elevated IOP, but no optic neuropathy), $\mathrm{n}=60$; and primary angle closure glaucoma (PACG) $\left(\$ 180^{\circ}\right.$ ITC with PAS, elevated IOP and optic neuropathy=60.Patient details such as age, sex, socioeconomic status was noted. A detailed history was taken regarding the duration and type of symptoms, systemic associations and treatment taken. Initial evaluation of the patients by history and clinical examination was performed and recorded in patients' data collection sheet.

\section{STATISTICAl AnAlysis}

- Data were processed and analyzed using computerbased software SPSS (Statistical Package for Social Sciences) for windows version 22. Unpaired t-test was used to compare quantitative variables. Variables were expressed as range and mean \pm SD. $\mathrm{p}$ value $<0.05$ were taken significant. Students' $t$ test, Pearson's correlation coefficient test, multivariate logistic regression analysis and Fisher's exact test as applicable.

\section{RESUlts}

In table-1 shows age distribution of the patients where most of the patients $(47 \%)$ belongs to age group 50-60 years. The following table is given below in detail:

Table-1: Age distribution of the patients

\begin{tabular}{|l|c|l|}
\hline Variable & Distribution & Percentage (\%) \\
\hline Age group & $40-50$ & 35 \\
\cline { 2 - 3 } & $50-60$ & 47 \\
\cline { 2 - 3 } & $60-70$ & 18 \\
\hline
\end{tabular}

In figure-2 shows gender distribution of the patients where male was $70 \%$ and female was $30 \%$. Male patients were $58 \%$ higher than female. The following figure is given below in detail:

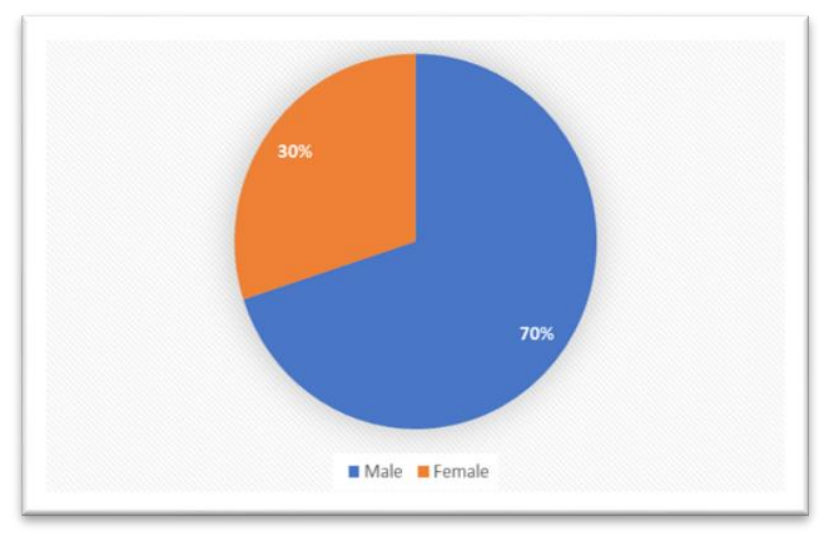

Fig-2: Gender distribution of the patients

In table-3 shows residential area distribution of the patients where $78 \%$ patients belong to urban area The following table is given below in detail

Table-3: Residential area distribution of the patients

\begin{tabular}{|l|c|}
\hline Residential area & \% \\
\hline Urban & $78 \%$ \\
\hline Rural & $12 \%$ \\
\hline
\end{tabular}

In table-3 shows clinical characteristics of the patients where $42 \%$ percent of the patients had undergone bilateral LPI. The following table is given below in detail:

Table-3: Clinical characteristics of the patients

\begin{tabular}{|l|l|}
\hline Variable & mean \pm SD, $\%$ \\
\hline \% of eye: & $23 \%$ \\
right eye & $35 \%$ \\
left eye \\
bilateral eye & $42 \%$ \\
\hline Mean baseline iOP (mmhg) & $19.49 \pm 11.1$ \\
\hline Mean post-laser iOP (mmhg) & $14.31 \pm 7.8$ \\
\hline $\begin{array}{l}\text { Diagnosis } \\
\text { Primary angle closure suspect, }\end{array}$ & $34 \%$ \\
\hline Primary angle closure & $11 \%$ \\
\hline Primary angle closure glaucoma & $51 \%$ \\
\hline Uveiticglaucoma & $6 \%$ \\
\hline
\end{tabular}

In table-4 shows mean power use by year where mean power used in primary angle closure glaucoma was $132 \pm 127.8$. The following table is given below in detail: 
Table-4: Mean power use by year

\begin{tabular}{|l|l|l|l|}
\hline Variable & $\mathbf{1}^{\text {st }}$ year & $\mathbf{2}^{\text {nd }}$ year & $\mathbf{3}^{\text {rd }}$ year \\
\hline Mean power used in primary angle closure suspect & $76.0 \pm 57.9$ & $76.0 \pm 57.9$ & $72.3 \pm 68.2$ \\
\hline Mean power used in primary angle closure & $143.5 \pm 72.5$ & $143.5 \pm 72.5$ & $87.9 \pm 41.1$ \\
\hline Mean power used in primary angle closure glaucoma & $87.9 \pm 41.1$ & $136.6 \pm 86.4$ & $132 \pm 127.8$ \\
\hline
\end{tabular}

In figure-3 shows complication rates by yearwhere $2 \%$ produced hyphema in $1^{\text {st }}$ year, followed by $1 \%$ produced hyphema in ${ }^{2 n d}$ year, no patients found in $3^{\text {rd }}$ year. The following figure is given below in detail:

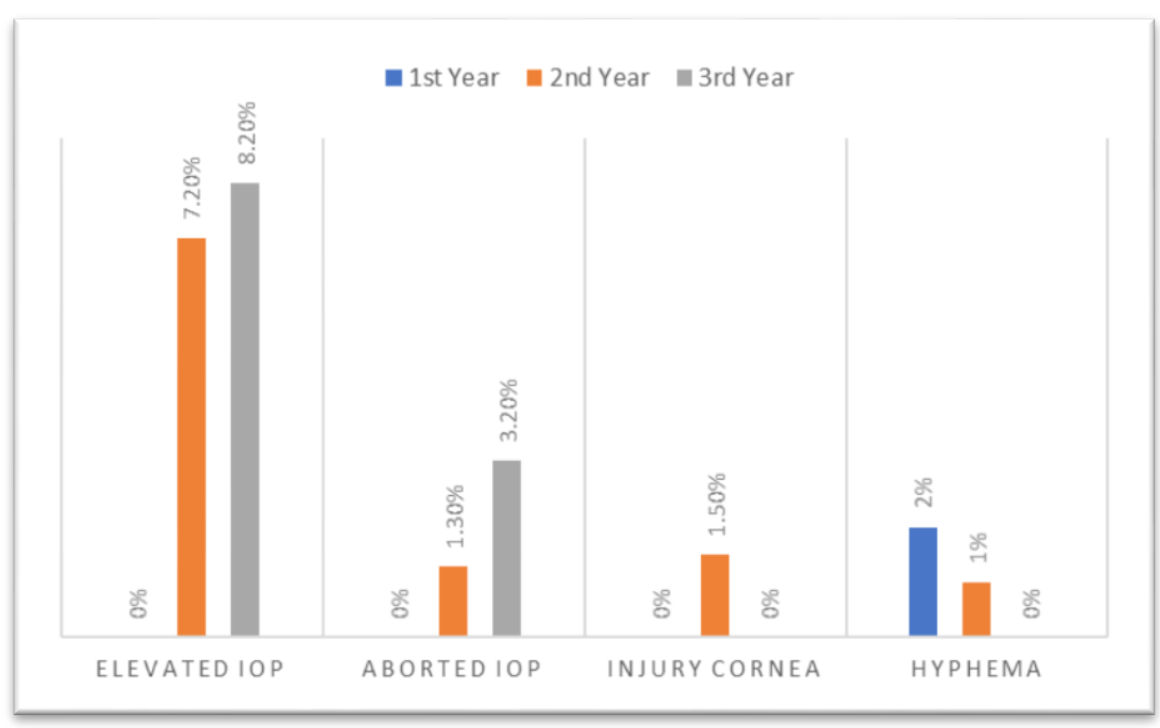

Fig-3: Complication rates by year

In figure-4 shows visual acuity of the patientswhere on the basis of Logmar chart, mean percentage of visual acuity where before treatment visual acuity of the primary angle closure suspect was $81 \%$, which was $3 \%$ increased after treatment, $84 \%$.The following figure is given below in detail:

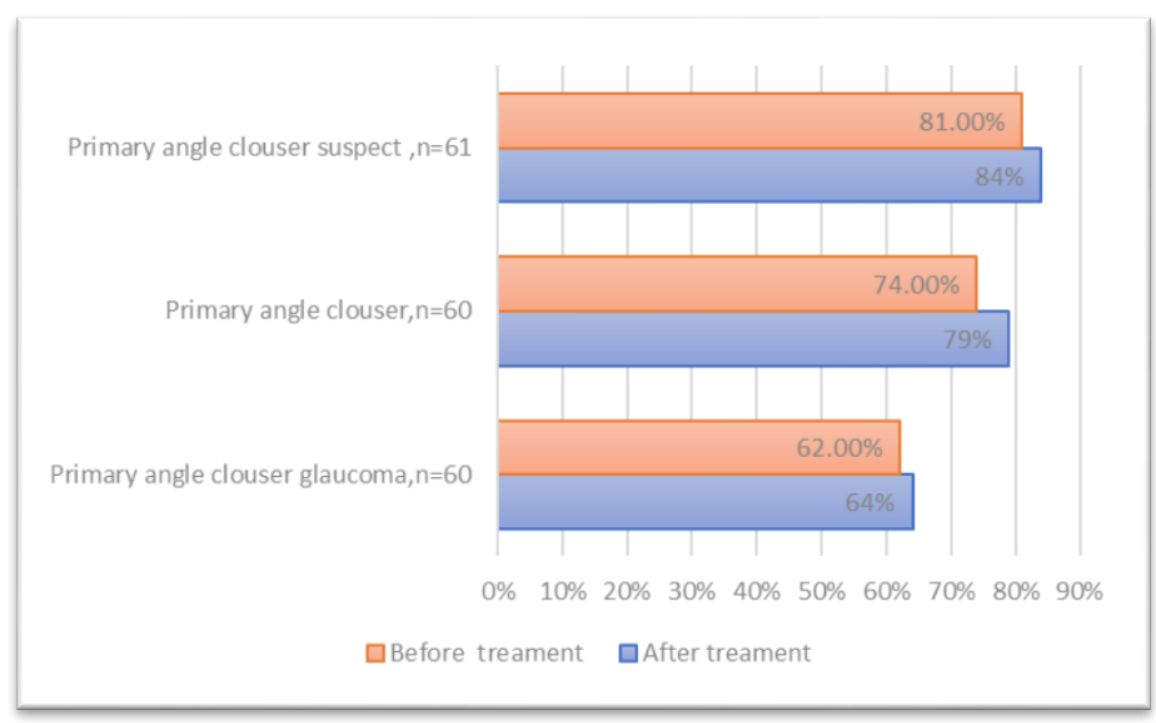

Fig-4: Distribution of the patients on the basis of visual acuity.

\section{DiscUSSION}

In our study most of the patients (47\%) belongs to age group 50-60 years. Which is supported by other study where $50 \%$ patients belong to age group
50-60 years [5]. In this study $42 \%$ percent of the patients had undergone bilateral LPI. Which similar to many studies [6-7]. 
Where $2 \%$ produced hyphema in $1^{\text {st }}$ year, followed by $1 \%$ produced hyphema in ${ }^{2 n d}$ year, no patients found in $3^{\text {rd }}$ year which is comparable to the $8.9 \%-34.6 \%$ reported in the literature [8-10].

When the overall complication rates between the groups were analyzed, there was no significant difference betweenthe groups. In one study reported that, inflammation, hyphema, corneal decompensation, cataract formation, IOP elevation, retinal detachments and cystoid macular edema is more common with higher total Nd: YAG energy use in LPI procedures [1, $2,7]$.

During the study, on the basis of Logmar chart, mean percentage of visual acuity before treatment in primary angle closure suspect was $801 \%$, which was $3 \%$ increased after treatment, 84\%. But in primary angle closure glaucoma before treatment it was $62 \%$, after treatment only $2 \%$ was increased. Which was quite similar to other studies [6-8].

Several studies over the years have shown that as IOP rises above $21 \mathrm{~mm} \mathrm{Hg}$, the percentage of patients developing visual field loss increases rapidly, most notably at pressures higher than $26-30 \mathrm{~mm} \mathrm{Hg}$. A patient with an IOP of $28 \mathrm{~mm} \mathrm{Hg}$ is about 15 times more likely to develop field loss than a patient with a pressure of $22 \mathrm{~mm} \mathrm{Hg}$ [7-9]. It is recommended that the iridotomies are created using the lowest laser energy necessary to minimize complications [10].

\section{Conclusion}

From our study we can conclude that, laser iridotomy can be use as beneficial tool for the clinical treatment of early primary angle-closure glaucoma which can effectively reduce the intraocular pressure and improves the acuity level of patient. Early treatment by laser iridotomy may also reduce the risk rate to develop primary angle glaucoma.

\section{REFERENCES}

1. Laser Peripheral Iridotomy for Pupillary-block glaucoma. American Academy of Ophthalmology. Ophthalmology. 1994;101(10):1749-1758.

2. Robin AL, Pollack IP. A comparison of neodymium: YAG and argon laser iridotomies. Ophthalmology. 1984;91(9):1011-1016.

3. Accreditation Council for Graduate Medical Education. ACGME oph-thalmology surgery case logs national data report: 2014-2015. 2015. Available

from: http://www.acgme.org/Portals/0/PDFs/240_Nationa 1_Report_Program_Version.pdf. Accessed May 1, 2017.

4. Vera V, Naqi A, Belovay GW, Varma DK, Ahmed II. Dysphotopsia after temporal versus superior laser peripheral iridotomy: a prospective randomized paired eye trial. Am J Ophthalmol. 2014;157(5):929-935.

5. Tarongoy P, Ho CL, Walton DS. Angle-closure glaucoma: the role of the lens in the pathogenesis, prevention, and treatment. Survey of ophthalmology. 2009 Mar 1;54(2):211-25.

6. Lewis R, Perkins TW, Gangnon R, Kaufman PL, Heatley GA. The rarity of clinically significant rise in intraocular pressure after laser peripheral iridotomy with apraclonidine. Ophthalmology. 1998;105(12):2256-2259.

7. Jiang Y, Chang DS, Foster PJ, He M, Huang S, Aung $T$, Friedman DS. Immediate changes in intraocular pressure after laser peripheral iridotomy in primary angle-closure suspects. Ophthalmology. 2012 Feb 1;119(2):283-8.

8. Schwartz LW, Moster MR, Spaeth GL, Wilson RP, Poryzees E. Neodymium-YAG laser iridectomies in glaucoma associated with closed or occludable angles. Am J Ophthalmol. 1986;102(1):41-44.

9. World Health Organization. Fact Sheet No. 282. Visual impairment and blindness June 2012. http://www.who.int/mediacentre/factsheets/fs282/e n.Google Scholar

10. Alsagoff Z, Aung T, Ang LP, Chew PT. Long-term clinical course of primary angle-closure glaucoma in an Asian population. Ophthalmology. $2000 \mathrm{Dec}$ $1 ; 107(12): 2300-4$. 